\title{
Investigating the Techno-economic Utility of Integrating an Optimized PV/diesel Hybrid System in an Entire Oil Field in the Western-dessert in Egypt
}

\author{
Mohammad M. El-Yamany ${ }^{1,}$, Sameh O. Abdullatif ${ }^{2}$ and Hani A. Ghali ${ }^{2}$ \\ ${ }^{1}$ Faculty of Energy and Environmental Engineering, The British University in Egypt (BUE). \\ ${ }^{2}$ FabLab in the Center for Emerging Learning Technologies (CELT) and Faculty of Engineering, The \\ British University in Egypt (BUE). El-Sherouk 11837, Cairo, Egypt
}

\begin{abstract}
Artificial lifting is considered as the most common technique in oil and gas production industry. However, from the electrical energy consumption prospective, artificial lifting is a heavy consumer. In the absence of a grid, oil and gas stack holders are forced to utilize diesel generator for energy production. Herein, an added cost of operation and maintenance is included in the oil production cost. The purpose of this work is to develop a systematic optimization methodology for utilizing renewable energy resources, specifically Photovoltaic (PV), in Oil \& Gas Industry. The study has been applied on an entire oil field in the Egyptian western dessert. The load is operated with an integrated solar-assisted system and stand-alone diesel generator. The annual energy requirements using the Levelized cost of energy (LCOE) for ten sucker rod pumping units have been evaluated. A metaheuristic optimizer (Water Cycle Optimization Technique WCOT) has been utilized to optimize the PV contribution in the hybrid PV/diesel system proposed. Moreover, centralized, and distributed generation systems have been investigated technically and economically. The results have shown that the hybrid centralized system can provide up to $62 \%$ reduction in the LCOE with respect to the running diesel generator 24/7 system.
\end{abstract}

Key-Words: - PV/diesel systems, Sucker-rod pumping, LCOE, Techno-economic feasibility, Metaheuristic Optimization.

Received: December 2, 2020. Revised: May 4, 2021. Accepted:May 27, 2021. Published: June 13, 2021.

\section{Introduction}

The recent fall in oil prices motivates oil and gas companies to optimize their production strategies and minimize their expenses while at same time, optimally extract oil in a cost-effective way [1]. One of the oil and gas industries in Egypt real challenges now is to sustain production in mature oil fields and maximize reserves [2]. In order to increase the production efficiency, applying artificial lifts is utilized to maximize petroleum resources while ensuring the most efficient use of existing stocks [35]. In Egypt, there are more than 1000 sucker rod pumping systems [6]. Accordingly, optimizing the electrical consumption of these pumps can significantly attribute on the overall production cost. The rapid electrification of oil fields in remote areas - often too far to expand the grid - was achieved mainly by installing decentralized diesel generating unit (DG) [7, 8]. 100\% diesel fuel systems have the benefits of using a proven and reliable technology that guarantees an electricity generation that is technically dis-patchable and available ondemand [9]. However, the capacity to operate load does not always equate to the availability of fuel for the generator in a rural setting. The isolated and often inaccessible conditions in rural areas make fuel very difficult to deliver, particularly if a system is required for several hours. It is also important to take account of local environmental impacts. For the $O \& G$ business itself, maintenance and operation are considered as the key disadvantages in DG alternative $[10,11]$.

Integrating renewable energy technologies in the oil and gas industry brings reduction in energy cost and reduction in greenhouse gas emissions [12-14]. Therefore, there is a global trend to shift toward the renewable energy in the oil and gas industry which appears in some of the major oil companies' investments. The author of [15] shows that 5 of the 8 major petroleum companies already started the investment in the renewable energy. Bloomberg statics states that both BP and Eni already devoted 200 million USD in the renewable energy sector while Total already spent around 500 million USD. Statoil also devoted 600 million USD, and Shell invested the largest share with 2 Billion USD in the renewable industry [16].

Accordingly, previous attempts in literature have showed the utility of utilizing renewable energy for electrical energy production in oil and gas fields. The author of [17] was seeking to optimize an integrated hybrid PV/diesel generator system for zero load 
rejection in Malaysia. The technical requirements of the optimization process were not to let the blackout time to exceed $1 \%$ from the total year supply. The research was targeting to calculate the optimum capacities of each power source with the energy storage units, to supply the load efficiently. The research used the graphical solution to solve the optimization problem. The Author considered several configurations and compared between them to find the best outfit for the hybrid power supply. The result showed that the hybrid PV/DG system was more feasible than the stand-alone PV system or the standalone DG. The stand-alone PV system cost was US\$ 205,135; the stand-alone DG was US\$206,095 to supply the same load. Meanwhile, the hybrid PV/Diesel and battery system cost was US\$ 130,129 to supply the same load which means that the total generation cost reduced by $35 \%$. However, the research did not consider the system in non-tropical areas or the harsh environment of the desert such as in the Egyptian desert.

On the other hand, the research mentioned in [18] discussed a real case study and implementation on involving the solar PV system with the DG in a remote oil field in the Egyptian western desert. The aim of the study was to improve the efficiency of the oil production process in the islanded system. The integration of the PV source in the generation system increased the robust level of the system and the reliability level of the power supply in hard climate conditions (sudden temperature drop at the late night, the high temperature at the morning and the sandy environment). All this was without any energy storage system, and it allowed the system to continuously produce the oil without any disturbance. The system saved over 15000 liters of diesel and reduced the $\mathrm{CO} 2$ emissions by 40 tons/yr. (12\% reduction). Despite that, the research did not mention the total system cost, the LCOE or even the economic parameters or terms that have been used in the study.

The study that has been presented in [19] focused on the economical factor of the study with sustaining the technical term within the acceptable limits. The hybrid system idea was to depend on the renewable energy only without any conventional power sources. The research main target was to develop a system that can reduce the oil production cost to the lowest possible limit. Sucker-rod pump artificial lift simulators (QRod ${ }^{\mathrm{TM}}$ and PROSPER ${ }^{\mathrm{TM}}$ ) has been used to calculate the energy required for the well oil production with all the pumping production considerations, either intermittent or continuous. HOMER software has been used to optimize the system components in different configurations to decrease system costs. After comparing between the stand-alone PV system, the stand-alone wind, the hybrid combination between both, and the hybrid combination with energy storage system, it has been found that the hybrid PV/wind/battery system was the best feasible configuration. The chosen system used a storage capacity of $0.56 \mathrm{kWh} / \mathrm{yr}$., NPC of US\$ $145,150.50$, LCOE of US $\$ 0.51 / \mathrm{kWh}$ and operating cost of US\$3,056.04/yr. On the other hand, the work presented theoretical calculations to design the power system, where no real measured data were presented. Meanwhile, the conditions and the assumptions used to size the power system were not mentioned. The study also did not consider applying the research outcomes on a larger system (entire field), which may lead to different results.

The Author of [20] applied an intelligent technique that involves Decision Tree as an optimization tool to create a relation between the output power and weather conditions used for optimizing power productions for different operation points. This study was achieved through using real data which includes power data from PV systems and weather data. The results showed that the accuracy of the model is $93.425 \%$ during the validation set and $82.01 \%$ during the training phase.

The author of [21] proposed three methods through using different approaches such as decision tree, linear regression algorithm, and random forest in order to mine and predict the output power of the renewable energy. These methods were performed to overcome the fluctuation through optimizing the control accuracy of solar panel position. The results exhibited that the accuracy of predication on the data test set through using decision tree is $39 \%$, the accuracy of linear regression algorithm is $61 \%$, and the accuracy of random forest is $66 \%$. On the other hand, the accuracy of predication in solar dip through using decision tree is $55 \%$, the accuracy of linear regression algorithm is $48 \%$, and the accuracy of random forest is $67 \%$.

All previous attempts did not show a complete optimized techno-economic feasibility with considering sustainability issues. Accordingly, we consider such an optimization problem as a literature gap.

In the current feasibility study, we are investigating the applicability of integrating $\mathrm{PV} /$ diesel hybrid system in a running oil field in the western desert in Egypt. The feasibility considers both technical as well as economic prospective. Real data captured from the in-field measurements have been used to evaluate the sucker rod pump implemented and the liquid production rate across ten wells in the field under test. Firstly, optimization for 
the PV contribution in the hybrid system is demonstrated. Secondly, the concluded optimum configuration is evaluated over both distributed and centralized systems. The presented optimization model can be considered as a novel approach where metaheuristic optimizer is integrated with PV sizing model for sucker road pumping systems. This paper would be of interest for a broad readership including theoreticians and experimentalist dealing with electric energy problems in oil and gas industry as well as solar energy systems. It combines a useful experimental data with the discussion of a new figure of merit to evaluate the performance of sucker-rod pumping system through well lifetime.

\section{Field Under feasibility Study}

\subsection{Field parameters}

In a remote place in the western desert of Egypt, there is an oil field represented by multiple sucker rod pumping systems (SRPs). These SRPs, which are also called "beam pumping", provide mechanical energy to lift the oil from the bottom hole of the well to the surface. Due to its simplicity, efficiency, and easiness, it is the most common way to lift the oil in the last stage of the primary recovery phase of the well, such as our case under investigation. This stage has a very low bottom-hole pressure; therefore, the SRPs is used to pump the oil up and maximize oil production rates. It is also suitable for slim holes, multiple completions, high-temperature, and viscous oils. SRPs design varies from one well to another; therefore, there is also a difference in their power needs. Our case study field consists of 10 different wells with different specifications, and each well is operated with own SRP.

In the next sub-section, a complete theoretical analysis for the SRP power consumption is presented in terms of the well specification.

\subsection{Sucker rod pump power calculation}

To estimate the load power along with its associated power generation system, some parameters must be taken into consideration. These parameters are the liquid production rate, the specific gravity of the produced liquid, the dynamic liquid level in the well (pump depth), the weight of sucker rod string, the stroke length, and the pump speed [22]. All these parameters have a direct impact on the sucker rod energy consumption. Table 1 represents the needed specifications for the ten wells in the field under test. The electrical power needed to operate SRPs is proportional to the hydraulic horsepower. Hydraulic horsepower is defined as the theoretical work required to lift the well fluids from the net depth, which can be calculated by [22] :

$\mathbf{H}_{\text {hydr }}=7.36 \times 10^{-6} \times \mathbf{Q} \times \mathbf{G} \times \mathbf{L}_{\text {dyn }}$

where $\mathbf{H}_{\text {hydr }}$ is the hydraulic horsepower required for lifting the liquid, $\mathbf{Q}$ is the liquid production rate, $\mathbf{G}$ is the specific gravity of the produced liquid and $\mathbf{L}_{\mathbf{d y n}}$ is the dynamic liquid level in the well. When the pump is set at the working fluid level, $\mathbf{L}_{\mathbf{d y n}}$ equals the pumping setting depth. The main down-hole energy losses in the SRPs are caused by the friction in the pump and rod string.

The equation for calculating friction horsepower losses can be illustrated by [22]:

$\mathrm{H}_{\mathrm{f}}=6.31 \times 10^{-7} \times \mathrm{Wr} \times \mathrm{S} \times \mathrm{N}$

where $\mathbf{H}_{\mathbf{f}}$ is the friction horsepower to overcome friction losses, $\mathbf{W r}$ is the weight of sucker rod, $\mathbf{S}$ is the stroke length, and $\mathbf{N}$ is the pump speed.

Table 1. Mechanical specifications of the overall oil field

\begin{tabular}{|c|c|c|c|c|c|c|}
\hline well & $\begin{array}{c}(\mathrm{Q}) \\
\text { Flow rate } \\
\text { (bbl./Day) }\end{array}$ & $\begin{array}{c}(\mathrm{G}) \\
\text { specific gravity } \\
\left(\mathrm{kg} / \mathrm{m}^{3}\right)\end{array}$ & $\begin{array}{c}(\mathrm{L}) \\
\text { Depth to } \\
\text { pump (ft) }\end{array}$ & $\begin{array}{c}\text { weight of sucker rod } \\
\text { string (lb.) }\end{array}$ & $\begin{array}{c}(\mathrm{S}) \\
\text { stroke } \\
\text { length (in) }\end{array}$ & $\begin{array}{c}\text { pump } \\
\text { speed } \\
(\mathrm{spm})\end{array}$ \\
\hline well 1 & 400 & 0.845 & 3950 & 8000 & 144 & 6.2 \\
\hline well 2 & 300 & 0.845 & 3645 & 7285 & 120 & 5.7 \\
\hline well 3 & 190 & 0.845 & 3978 & 8100 & 120 & 5.6 \\
\hline well 4 & 170 & 0.845 & 3650 & 7300 & 120 & 6.2 \\
\hline well 5 & 400 & 0.845 & 3782 & 7700 & 144 & 5.7 \\
\hline well 6 & 125 & 0.845 & 3925 & 7900 & 120 & 5.7 \\
\hline well 7 & 425 & 0.845 & 3654 & 7325 & 144 & 6.17 \\
\hline well 8 & 250 & 0.845 & 3995 & 8200 & 144 & 5.7 \\
\hline well 9 & 220 & 0.845 & 3390 & 7100 & 120 & 6.2 \\
\hline well 10 & 165 & 0.845 & 3500 & 7200 & 120 & 5.7 \\
\hline
\end{tabular}


The prime mover should be properly sized to provide adequate power to lift the production fluid. Additionally, properly sized prime mover overcome friction loss in the pump, the rod string, the polished rod, and the pumping unit. The power required for lifting fluid, overcoming friction losses, and any unpredictable losses within the surface equipment is called "Brake horsepower" Thus, the required prime mover power ( Mechanical Power) can be expressed as [22]:

$\mathbf{H}_{\mathrm{b}}=\mathbf{F}_{\mathrm{s}}\left(\mathbf{H}_{\mathrm{hydr}}+\mathbf{H}_{\mathrm{f}}\right)$

where $\mathbf{H}_{\mathbf{b}}$ is the brake horsepower of the prime mover and $\mathbf{F}_{\mathbf{s}}$ is a safety factor of $1.25-1.50$ based on manufacturer decision. In the current study, a safety factor of 1.5 was chosen to account for any surface power losses.

For an electric motor, the nameplate rating must be larger than the brake horsepower to account for heat losses in the motor due to cyclic loading imposed by rod pumping. Consequently, the motor rating $\mathbf{P}_{\mathbf{M}}$ can be expressed by:

$\mathbf{P}_{\mathbf{M}}=\frac{0.745 * \mathrm{H}_{\mathbf{b}} * \mathrm{CLF}}{\boldsymbol{\eta}_{\text {motor }}}$

where $\mathbf{C L F}$ is the cyclic load factor, which assumed as 1.3 , and $\boldsymbol{\eta}_{\text {motor }}$ is the motor efficiency that considered as $78 \%$. The motor rating represents the calculated electrical power in $(\mathrm{kW})$ required for the SRPS.

\subsection{Calculated and actual sucker rod pump power}

Following the theoretical procedure demonstrated in the previous section, the calculated power can be extracted for the ten given wells, with utilizing the mechanical parameters illustrated in table 1 . Alternatively, table 2 summarizes the electrical specifications of every well of the ten wells under study, based on real in-field measured data. The power of the prime movers in the field varies from 40 hp to $60 \mathrm{hp}$, while the voltage is $380 \mathrm{~V}$ (three-phase). The upstroke current varies from $24 \mathrm{~A}$ to $67 \mathrm{~A}$, while the down-stroke current varies from $17 \mathrm{~A}$ to $33 \mathrm{~A}$. All the field motors have power factor range starts from 0.81 and it reaches 0.88 at the motor best condition. The actual consumed power of the SRPs could be estimated, where the power supply system is designed accordingly.

The input power in the case of the SRPs is the electrical power from the power source, while the mechanical power that is used in the process of lifting the oil is the output power. The previous subsection showed the procedure of calculating the electrical powers in SRPs of the targeted field. By comparing the calculated power with the actual measured infield power mismatchings are observed. Knowing the mismatching, if existed, between the actual and the calculated power is very important for the system feasibility. Hence, figure 1 presents the values of both the calculated and the actual powers. It is obvious that the actual power is higher than the calculated power while both should be the same.

The mismatching between the two curves is due to some mechanical losses, which can be justified by the safety factor. The power losses occurring in the well (downhole losses) and in the surface machinery (surface losses). In the downhole losses, there is mechanical friction between the sucker rod pump's barrel and plunger. In addition, sand associated with the produced oil increases the specific gravity of the oil. Moreover, sand increases the friction while sucker rod string movement, where the surface losses occur at several places from the polished rod to the electrical connections of the prime mover, these can be classified according to their occurrence as mechanical losses in the gearbox, v-belt drive, and losses in the prime mover.

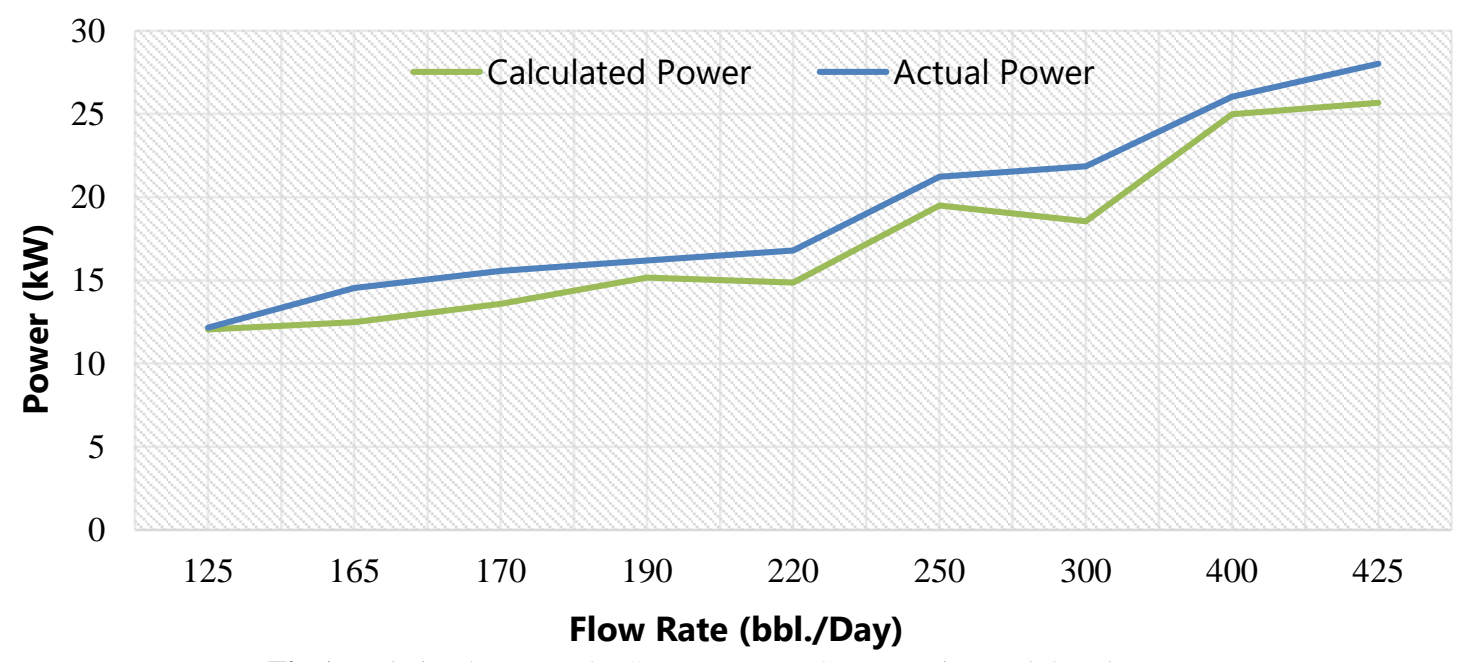

Fig.1: Relation between the System Power Consumption and the Flow Rate 
Table 2. Electrical specifications of the overall oil field

\begin{tabular}{|c|c|c|c|c|c|}
\hline \multirow{2}{*}{ Well \# } & \multirow{2}{*}{$\begin{array}{l}\text { Motor } \\
\text { (hp) }\end{array}$} & \multirow{2}{*}{$\begin{array}{l}\text { Voltage } \\
\text { (V) }\end{array}$} & \multicolumn{2}{|c|}{ Current (A) } & \multirow{2}{*}{$\begin{array}{c}\text { Power } \\
\text { factor }(\mathrm{pf})\end{array}$} \\
\hline & & & Upstroke & Downstroke & \\
\hline well 1 & 60 & \multirow{10}{*}{380} & 67 & 30 & 0.86 \\
\hline well 2 & 40 & & 50 & 32 & 0.81 \\
\hline well 3 & 40 & & 38 & 22 & 0.82 \\
\hline well 4 & 40 & & 35 & 20 & 0.86 \\
\hline well 5 & 60 & & 60 & 32 & 0.86 \\
\hline well 6 & 40 & & 24 & 18 & 0.88 \\
\hline well 7 & 60 & & 66 & 33 & 0.86 \\
\hline well 8 & 60 & & 45 & 30 & 0.86 \\
\hline well 9 & 40 & & 38 & 20 & 0.88 \\
\hline well 10 & 40 & & 35 & 17 & 0.85 \\
\hline
\end{tabular}

\section{PV/diesel hybrid alternatives}

The enewable energy source that is considered in this study is based on a solar PV system. The hybrid systems that depend on photovoltaic (PV) are considered the most popular renewable generation system among any other type of renewable energy systems. The main advantages of this technology are the low maintenance costs and low pollutant emissions. The schematic diagram of this system is shown in figure 2 . The feasibility highlights the implementation of PV/diesel systems with various PV contributions covering from $0 \%-\mathrm{PV}$ (stand-alone diesel generator system, see figure $2 \mathrm{a}$ ) to $100 \%-\mathrm{PV}$ (stand-alone off-grid PV system, see figure $2 b$ ). The $0 \%$-PV system is considered the currently running system; accordingly, this system will be treated as the reference system in all comparisons (see figure 2a). On the other hand, two main topologies are discussed in the current study, including hybrid distributed generation system (HDGS) and hybrid centralized generation system (HCGS). In HDGS, each SRP will be supplied with an independent electric power supply, while in HCGS, a centralized system will be designed to supply the field.

\subsection{Stand-alone diesel generator (0\%-PV reference system)}

The currently running system in the field under test includes a $120 \mathrm{~kW}$ diesel generator per well. This diesel generator consumes $370 \mathrm{~L} / \mathrm{d}$ of fuel with 10 EGP/L and a renting cost of 1155EGP per day. The renting cost includes the maintenance and the spare parts change. Figure 2 a shows a schematic diagram for the stand-alone diesel generator system.

\subsection{Stand-alone PV system}

The other extreme scenario is to implement a 100\%PV off-grid stand-alone system. As displayed in figure $2 \mathrm{~b}$, the proposed stand-alone PV system consists of PV modules with batteries as a storage system which is the only source of electrical energy. While solar PV array has been sized to meet the required energy demand as mentioned in the previous section. As shown in table 3 , the technical specifications for the components of the proposed system have been composed of $340 \mathrm{~W}$ polycrystalline PV module, with open circuit voltage of $46.2 \mathrm{~V}$ and short circuit current of $9.4 \mathrm{~A}$. It has been integrated with a battery of $12 \mathrm{~V}$ and $150 \mathrm{Ah}$. In an attempt to match the requirement of the three phases sucker rod pump, a $27 \mathrm{~kW}$ (DC/AC) inverter of 3phases output has been used, with maximum input current of 47.7 A and AC output current of $40.9 \mathrm{~A} / 39.1$ A.

\subsection{Hybrid PV/diesel system}

In between the two extremes demonstrated in the previous two subsections, hybrid system combining the PV system $(340 \mathrm{~W})$ and the diesel generator system $(120 \mathrm{~kW})$ with various contributions for each can be implemented as exhibited in figure $2 \mathrm{c}$. To select the optimum configuration between the DG and the PV system, various points over the design space have been chosen based on the operating hours of each system. The purpose of this technology is providing electricity to remote areas with unstable mains supply by reducing diesel consumption, hence, achieving the sustainability factor into the system. 


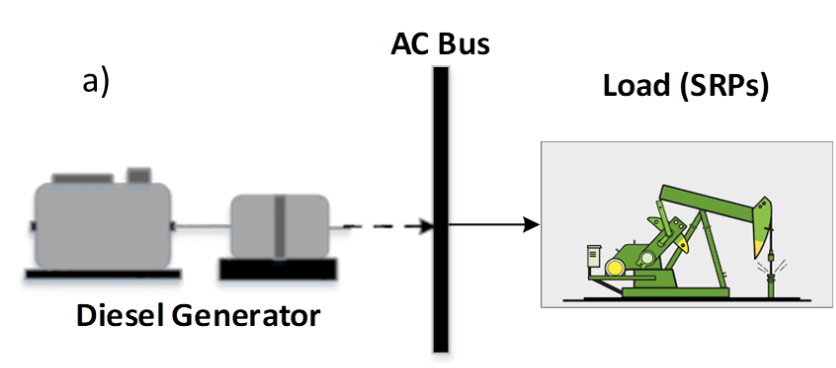

b)
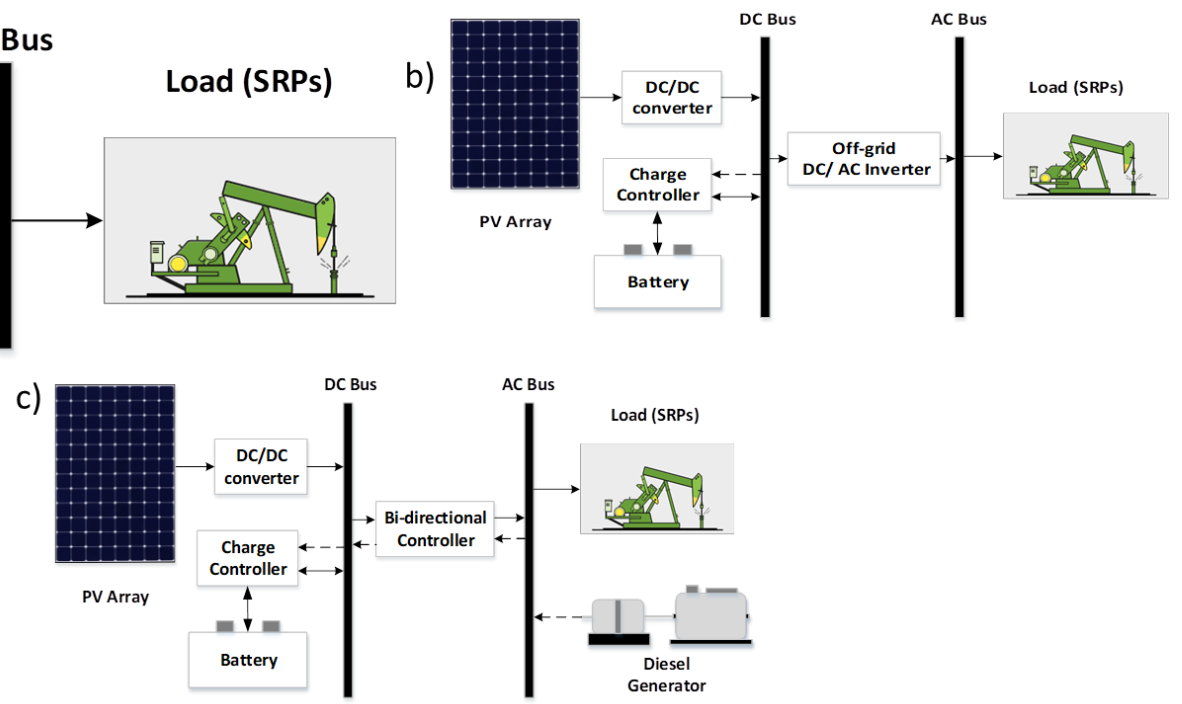

Figure.2: Different generation system alternatives for SRP under test, (a) 0\%-PV system (b) 100\%-PV system and (c) hybrid PV/diesel system.

Table 3. PV system specifications

\begin{tabular}{|l|l|}
\hline \multicolumn{2}{|c|}{ Solar Panel } \\
\hline Type & Poly Solar (Suntech) \\
\hline Max. Power (W) & 340 \\
\hline Operating Voltage (V) & 37.8 \\
\hline Operating Current (A) & 9 \\
\hline Module Area (m²) & 1.97 \\
\hline Max. Voltage (V) VDC Inatteries \\
\hline \multicolumn{2}{|l|}{} \\
\hline Nominal Voltage (V) & 1500 \\
\hline Nominal Capacity (Ah) & 150 \\
\hline Max. Capacity (Ah) & 83.4 \\
\hline Weight (Kg) & 34 \\
\hline \multicolumn{2}{|c|}{} \\
\hline Max. input current (A) IDC & 47.7 \\
\hline Max. array short circuit current (A) & 71.6 \\
\hline DC input voltage range (V) & $580-1000$ \\
\hline Max. Power Input (kWp) & 37.8 \\
\hline Max. Output Power (kW) & 27 \\
\hline Max. Output Current (A) & 40.9 \\
\hline
\end{tabular}

\subsection{PV system sizing}

The PV system sizing using the intuitive method is going through some steps to approach the final system value; thus, it is designed to cover the load needs. The main factors that have a significant effect on the system size are the load demand and the peak sun hours (PSH). The author in [23] used the following equations to calculate the total PV parameters and to get the size of the PV module in the system:

$$
P_{P V}=E_{L} S_{f} / \eta_{\text {inv }} \eta_{R} P S H
$$

where $\boldsymbol{E}_{\boldsymbol{L}}$ is the total energy demand per day, $\boldsymbol{S}_{\boldsymbol{f}}$ is safety factor that represents the losses of the dust, cable joints and cloudy times, $\boldsymbol{\eta}_{\boldsymbol{i n} \boldsymbol{v}}$ is inverter efficiency, $\boldsymbol{\eta}_{\boldsymbol{R}}$ is voltage regulator efficiency, and
PSH is peak sun hours in the proposed area. $P \boldsymbol{S H}$ of the case study location can be calculated based on the solar irradiation of its location. If there is any storage system connected with the power system, the size of this system could be calculated by:

$E_{B}=\frac{S_{f} * E_{L}}{\eta_{B} \text { DOD }}$

The following equation is being used to calculate the ampere hour $(\mathrm{AH})$ of the storage system.

$\mathbf{I}_{\mathbf{B}}=\mathbf{E}_{\mathbf{B}} / \mathbf{V}_{\mathbf{B}}$

where $\mathbf{E}_{\mathbf{B}}$ is the battery storage capacity in $\mathrm{Wh}, \boldsymbol{\eta}_{\mathbf{B}}$ is the battery efficiency, DOD: depth of discharge for the battery, $\mathbf{I}_{\mathbf{B}}$ is the battery storage ampere-hour 
in $\mathrm{Ah}$, and $\mathbf{V}_{\mathbf{B}}$ is the battery voltage. The system parameters that have been used in this research are listed in table 4.

Table 4. Parameters of the System Calculations

\begin{tabular}{|c|c|}
\hline System Parameters & Value \\
\hline Safety Factor (SF) & 1.25 \\
\hline Inverter efficiency ( $\eta$ inv) & 0.9 \\
\hline Voltage regulator efficiency $(\eta \mathrm{R})$ & 0.9 \\
\hline Peak Sun Hour (h/day) PSH & 5 \\
\hline Depth of discharge (DOD) & 0.5 \\
\hline SPV efficiency & 0.16 \\
\hline Battery efficiency $(\eta B)$ & 0.8 \\
\hline Solar radiation at STC $(\mathrm{W} / \mathrm{m} 2)$ Gref & 1000 \\
\hline Room temperature at STC $\left({ }^{\circ} \mathrm{C}\right)$ Tref & 25 \\
\hline Total Lifetime of the System (Year) LS & 20 \\
\hline
\end{tabular}

\subsection{PV/diesel system cost analysis}

To estimate the system parameters cost, three cost of every individual components must be considered. In [24] the Annualized Total Life Cycle Cost (ATLCC) of the system is calculated by:

$$
\text { ATLCC }=\sum_{\text {Device }} \mathbf{C}_{\text {cap,a }}+\mathbf{C}_{\mathbf{o} \& m, a}+C_{\text {rep,a }}+C_{s, a}
$$

where, $\mathbf{C}_{\mathbf{c a p}, \mathbf{a}}$ is the capital costs, $\mathbf{C}_{\mathbf{o} \& \mathbf{m}, \mathbf{a}}$ is the operation and maintenance costs, $\mathbf{C}_{\mathbf{r e p}, \mathbf{a}}$ is the replacement costs, and $\mathbf{C}_{\mathbf{s}, \mathbf{a}}$ is the salvage value. In this study the $\mathbf{C}_{\text {rep,a }}$ is counted inside the $\mathbf{C}_{\mathbf{o} \& \mathbf{m}, \mathbf{a}}$ while $\mathbf{C}_{\mathbf{s}, \mathbf{a}}$ is considered to be zero. Therefore, ATLCC has been formulated as follows:

$$
\begin{aligned}
& \mathrm{C}_{\text {cap }, \mathrm{a}}=\frac{\mathrm{C}_{\text {cap }}}{\frac{(1+\mathrm{ndr})^{\mathrm{L}_{s-1}}}{\mathrm{ndr}\left(1+\mathrm{ndr}^{\mathbf{L}_{\mathrm{s}}}\right.}}
\end{aligned}
$$

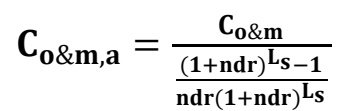

$$
\begin{aligned}
& \mathbf{n d r}=\left[\left(\frac{1+\text { interest } \%}{1+\text { inflation } \%}\right)-1\right]
\end{aligned}
$$

where $\mathbf{C}_{\text {cap }}$ and $\mathbf{C}_{\mathbf{o} \& \mathbf{m}}$ are the total capital cost, operating and maintenance expenses during the expected lifespan of the system, respectively. $\mathbf{L}_{\mathbf{s}}$ is the total lifetime of the according to the study, and $\mathbf{n d r}$ is the net of inflation rate discount.

To calculate the ATLCC of any system, the inflation and interest rates of the project location must be counted. Based on [25, 26], the weighted average inflation rate for Egypt from 1984 till 2021 is $11.45 \%$, while the interest rate in 2019 is $5 \%$ for the renewable energy projects based on the Central Bank of Egypt (CBE). For the cost equations, the inflation and the interest rates of Egypt need to be provided. The inflation rate has been taken as the weighted average for the 40 years as it will affect the income of the project. Meanwhile, the interest is using the rate of 2019 only as it is the year of the project loan. On the other hand, total capital costs of the system could be calculated as follows:

$$
\begin{aligned}
& \mathrm{C}_{\text {cap }}=\mathrm{C}_{\text {cap,PV }}+\mathrm{C}_{\text {cap,Inv }}+\mathrm{C}_{\mathrm{cap}, \mathrm{OC}}+\mathrm{C}_{\text {cap,Bat }}+ \\
& \mathrm{C}_{\text {cap }, \mathrm{C}}+\mathrm{C}_{\text {cap,DG }}
\end{aligned}
$$

where $\mathbf{C}_{\text {cap,PV }}, \mathbf{C}_{\text {cap,Inv }}, \mathbf{C}_{\text {cap,oc }}, \mathbf{C}_{\text {cap,Bat }}, \mathbf{C}_{\text {cap, }}$ and $\mathbf{C}_{\mathbf{c a p}, \mathbf{D G}}$ are the total capital cost for PV array, inverter, other costs, battery, the controller and diesel generator, respectively. The operation and the maintenance costs of the system could be calculated by following equation:

$$
\begin{aligned}
& \mathrm{C}_{\text {o\&m }}=\mathrm{C}_{\text {o\&m,PV }}+\mathrm{C}_{\text {o\&m,Inv }}+\mathrm{C}_{\text {o\&m,OC }}+ \\
& \mathrm{C}_{\text {o\&m,Bat }}+\mathrm{C}_{\text {o\&m,C }}+\mathrm{C}_{\text {o\&m,DG }}
\end{aligned}
$$

where $\mathbf{C}_{\mathbf{o} \& \mathbf{m}, \mathbf{P V}}, \mathbf{C}_{\mathbf{o} \& \mathbf{m}, \mathbf{I n v}}, \mathbf{C}_{\mathbf{o} \& \mathbf{m}, \mathbf{O C}}, \mathbf{C}_{\mathbf{o} \& \mathbf{m}, \mathbf{B a t}}, \mathbf{C}_{\mathbf{o} \& \mathbf{m}, \mathbf{C}}$ and $\mathbf{C}_{\mathbf{o} \& \mathbf{m}, \mathbf{D G}}$ are the total operating and maintenance cost for PV array, inverter, other costs, battery, the controller and diesel generator, respectively. The maintenance cost $\left(\mathbf{C}_{\mathbf{o} \& \mathbf{m}}\right)$ term includes some other costs $\left(\mathbf{C}_{\mathbf{o} \& \mathbf{m}, \mathbf{0}}\right)$, such as the dust cleaning cost. As the system will be installed in the desert, the dust will be deposited on the panels, which can easily affect the PV panel performance and efficiency. Therefore, a dust cleaner is imperative to clean the panels on a regular basis. This cleaner has five years lifetime and needs replacement every five years. Additionally, there will be some other costs involved during the lifespan of the system, including but not limited to; the labour cost, consumables...etc. Finally, the Levelized Cost of Energy (LCOE) (EGP/kWh) for the system of this study over 20 years, could be resulted from the following equation [27, 28]:

$\mathrm{LCOE}=\frac{\mathrm{ATLCC}}{\mathrm{E}_{\mathrm{L}}}$

\subsection{PV/diesel system optimization}

Seeking for an optimum operation point in terms of the PV contribution in the hybrid system under test, all possible design space points have been scanned with respect to LCOE. Parametric sweep optimization has been used based on the mathematical equations demonstrated in the previous sub-sections. This model investigates the relation between the DG and the PV system over the whole design space starting from 0\%-PV system to $100 \%$ PV. Such parametric sweep has been scripted using Matlab through customizing our previously developed Matlab code in [29, 30] to fit off-grid hybrid systems. Over and above, we introduce the water cycle optimization technique (WCOT) to optimize the system performance [31]. Our proposed fitness function is defined by: 
$\zeta_{\mathrm{LCOE}}=$

$\sqrt[3]{\left(\operatorname{LCOE}_{\mathrm{PV}}^{\varepsilon}\right)^{\left(\beta_{1}\right)} \times\left(\mathbf{L C O E}_{\mathrm{DG}}^{\varepsilon}\right)^{\left(\beta_{2}\right)} \times\left(\mathbf{L C O E}_{\mathrm{B}-\mathrm{DC}}^{\varepsilon}\right)^{\left(\beta_{3}\right)}}$

$\sum_{\mathrm{i}=1}^{3} \beta_{\mathrm{i}}=\mathbf{3}$

where $\beta$ is the weighting factor of the corresponding elements. Herein, a geometric average for these three parameters is introduced to optimize the proposed system. The three parameters are the Levelized cost of energy for the PV system, DG system and the added battery if needed. Consequently, the root mean square error (RMSE) [32] has been used to calculate the error between both optimization techniques used (parametric sweep and WCOT). The RMSE is calculated by:

$$
\text { RMSE }=\sqrt{\frac{1}{\mathrm{n}} \sum_{\mathrm{i}=1}\left(\frac{\mathrm{y}_{\mathrm{t}}-\mathrm{y}_{\mathrm{m}}}{\mathrm{y}_{\mathrm{t}}}\right)^{2}}
$$

where, $\mathbf{y}_{\mathbf{t}}$ is reference output, $\mathbf{y}_{\mathbf{m}}$ is model output, and $\mathbf{n}$ is the number of points.

\section{Results and discussions}

In this section, all techno-economic results are demonstrated in two successive subsections. Firstly, the optimization process for the PV contribution in the hybrid system proposed is presented, reaching an optimum PV/DG alternative. Secondly, a comparison between HDGS and HCGS takes place in terms of the LCOE and system utilization.

\subsection{PV/diesel system optimization results}

As mentioned earlier, both the parametric sweep model as well as WCOT are used in this research to optimize the PV contribution in the PV/DG system. As shown in figure 3 , the stand-alone diesel generator has the lowest LCOE till the PV contribution reaches $30 \%$, then the hybrid system takes the lead in the lowest LCOE value. This shows that the hybrid system before $30 \%$ of the PV system has no economic benefit to this research case study. Furthermore, there is an overlap at the point 54\% (PV system contribution), where the LCOE reaches its global minimum level. This concludes that the selection of the PV system contribution at $54 \%$ is the optimum techno-economic hybrid system configuration.

On the other hand, RMSE given in equation (17) is used to evaluate the two proposed optimization techniques. Herein, an overall error less than $5 \%$ is detected across the range of study $(0 \%$-PV to $100 \%$ $\mathrm{PV})$. The observed error is detected more toward the extreme left point (0\%-PV system), as in this region, two LCOE terms, in the fitting equation given in (15), collapse while $\mathbf{L C O E}_{\mathbf{D G}}^{\boldsymbol{\varepsilon}}$ glows up as the main dominating term.

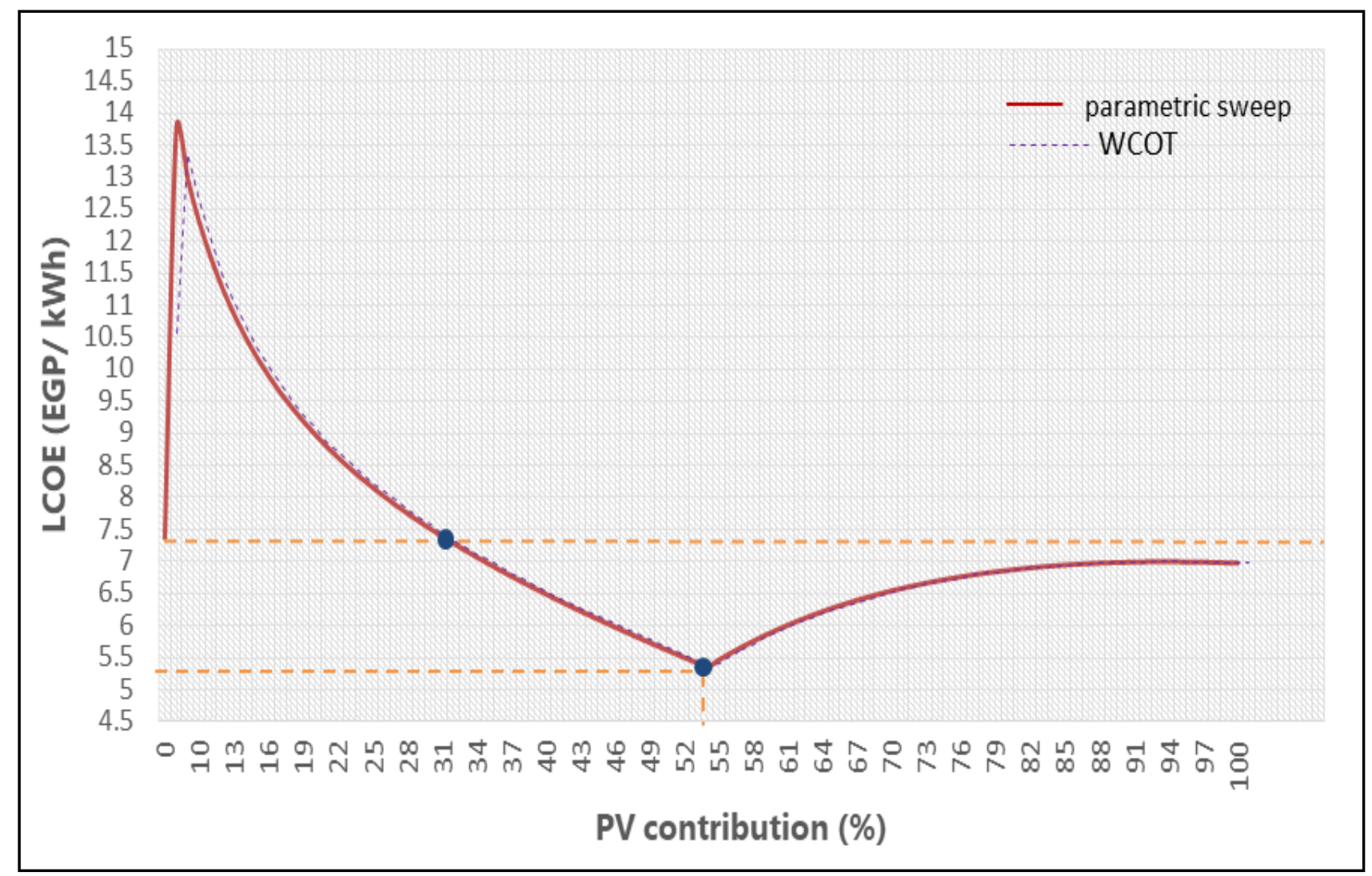

Figure.3: PV contribution optimization in PV/DG hybrid system, parametric sweep and WCOT data. 


\subsection{Distributed and centralized PV/diesel generation system}

As mentioned before, the energy share of the optimum PV system is $54 \%$ based on the optimum scenario result in the previous sub-section. Based on these results, this optimum model is applied over the ten wells in the field under both HDGS and HCGS topologies.

\subsubsection{Hybrid distributed generation system (HDGS)}

By following the techno-economic procedures that has been introduced for PV/diesel system analysis in the previous section, technical as well as economic outputs for the distributed generation system are listed in table 5. Additionally, figure 4 shows the relation between the total energy consumption and the PV system size against the liquid production rate. Herein, the size of the diesel generator for the 10 wells is constant. This is because the prime movers of the ten wells need a power source with a rate of less than $120 \mathrm{~kW}$; however, this is the smallest available generator size in the market. Therefore, 120 KW DGs are mostly oversized for the sucker rod pumping systems, and they are rented with the fixed rental cost. This leads to increases in the overall cost for the small sucker rod pumping systems rather than the large ones.

Figure 5 displays the PV system specifications for the whole field against the liquid production rate. As the flow rate increase, the area needs for the system increases, and the same happen for the PV panels number. The size of the inverter stays the same at two inverters for each sucker rod pumping system for the first four wells, and this is because of the fixed inverter rate that is chosen in this study. Then the number increased to three inverters then four based on the rated power for the energy sourced that is supplying the loads in the field. The total capital cost, the diesel consumption, and the diesel cost are directly proportional to the energy consumption of the sucker rod pumping systems (see figure 6).

Moreover, there is a drop in the LCOE with the increase of the flow rate while the total capital cost and the fuel cost are rising. This shows that as much the system size increases, the LCOE is going down. Therefore, it could be concluded that as larger the system size, the lower the cost of the energy produced. In addition to that, the oversized diesel generators that is used to supply the load has a dramatic effect on the changes in the LCOE.

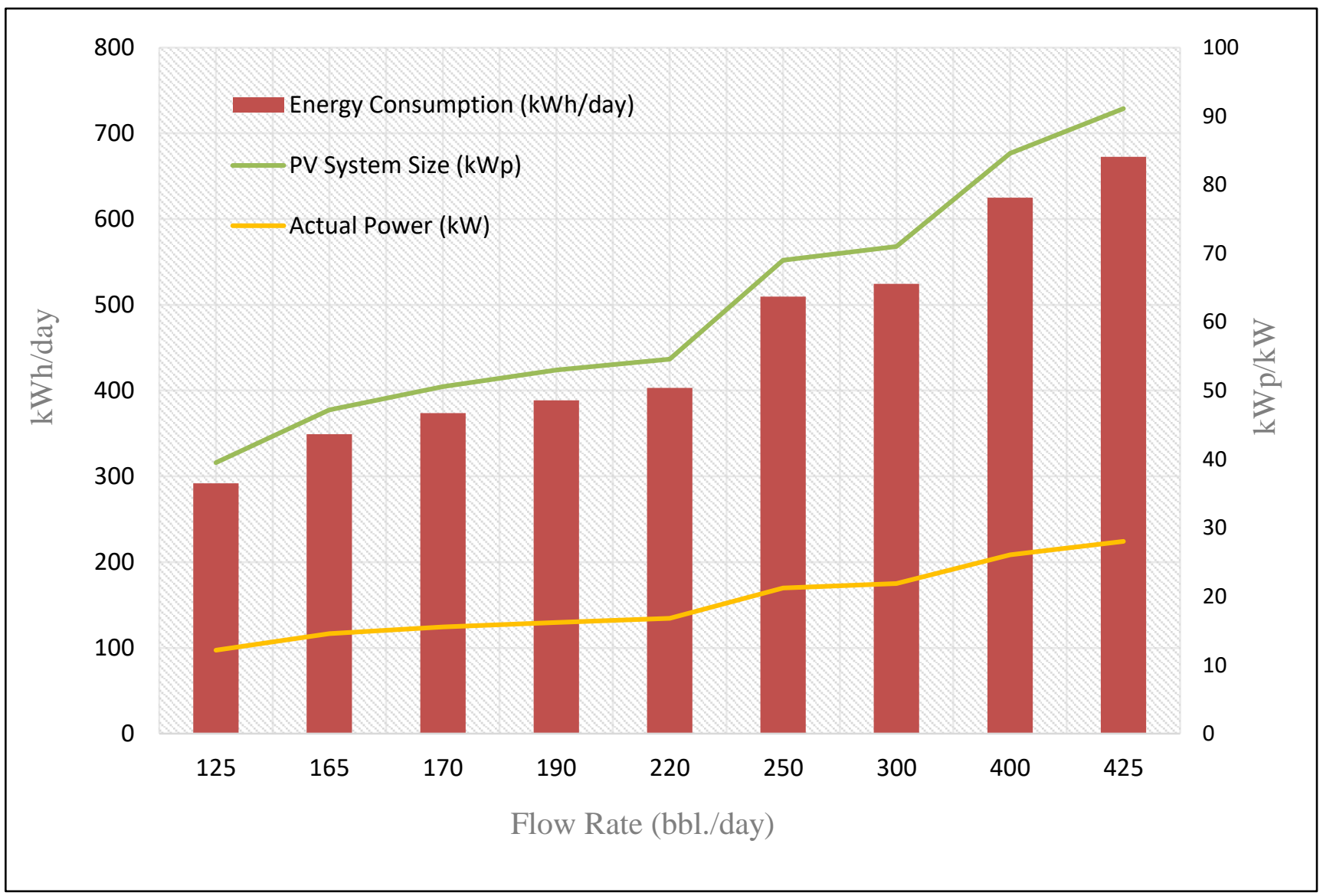

Figure.4: Technical outputs for the Whole Field using HDGS topology, total energy consumption and PV system size against oil flow rate for the ten wells under test. 


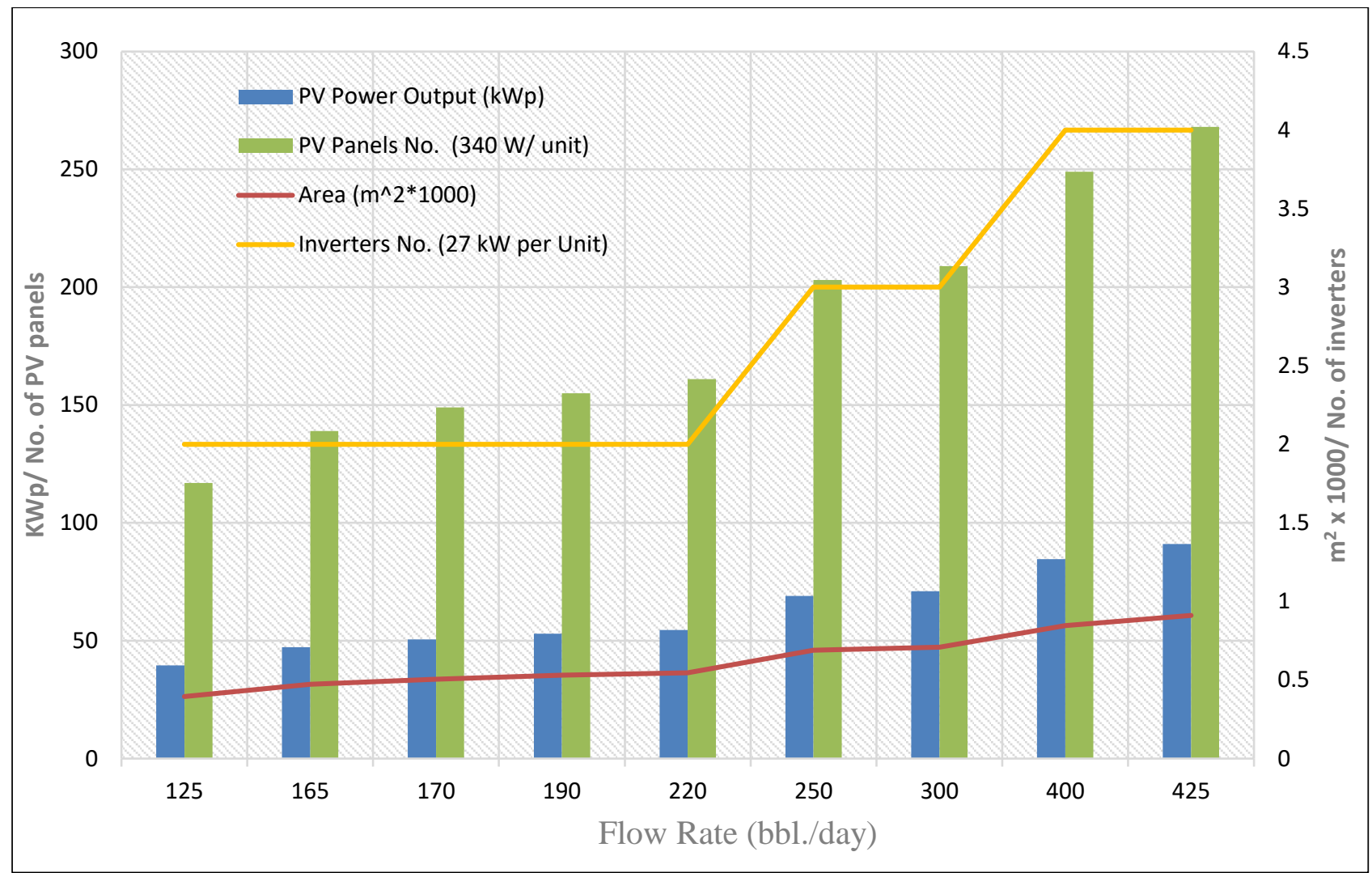

Figure.5: PV system specifications for the whole Field using HDGS topology

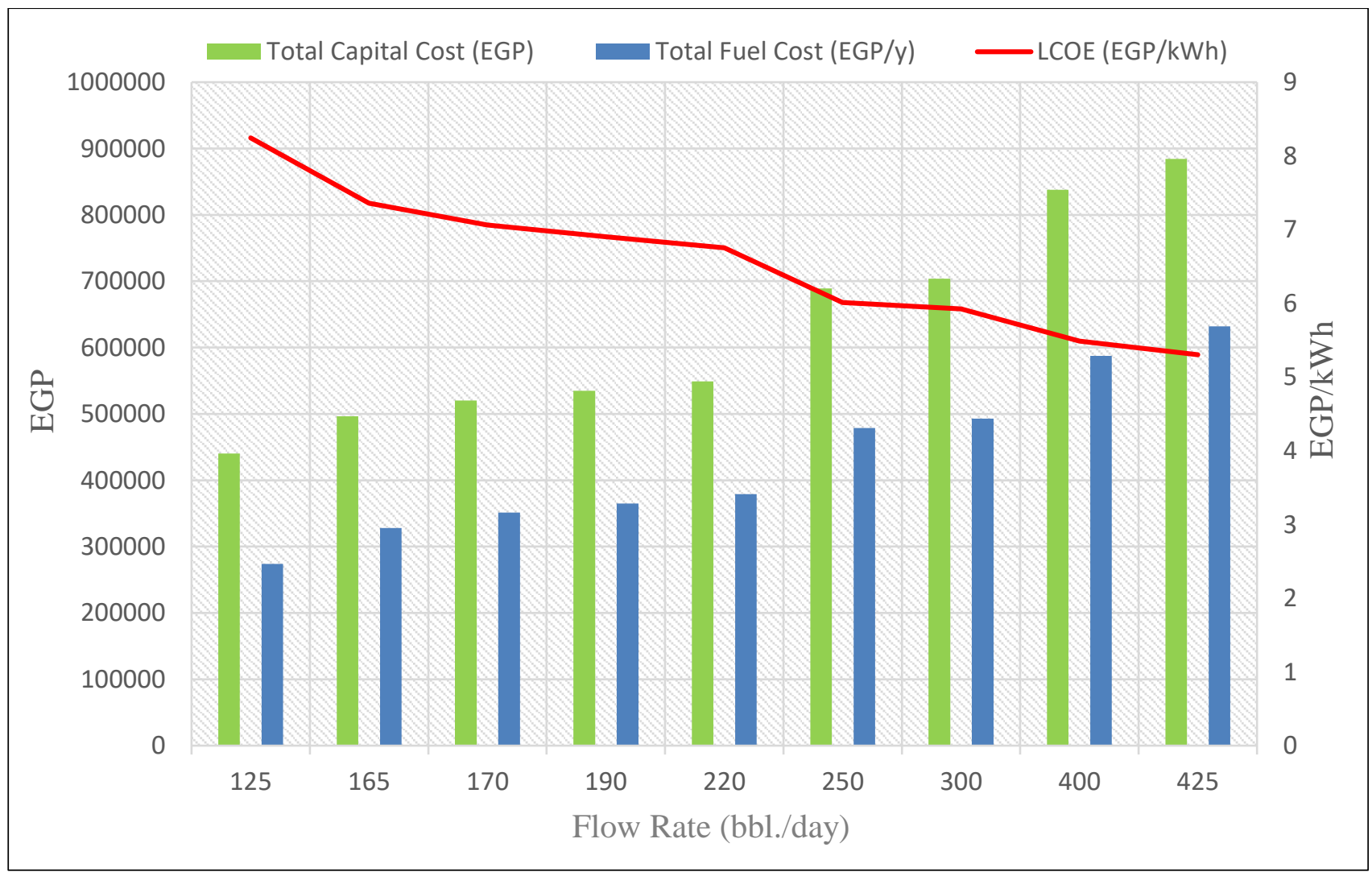

Figure.6: Cost Analysis for the whole Field using HDGS topology. 
Table 5. Techno-economic Parameters for the Field using HDGS topology.

\begin{tabular}{|c|c|c|c|c|c|}
\hline \multirow{2}{*}{ Parameters } & \multicolumn{5}{|c|}{ Well No. } \\
\hline & 1 & 2 & 3 & 4 & 5 \\
\hline Flow Rate (bbl./Day) & 400 & 300 & 190 & 170 & 400 \\
\hline Actual Power $(\mathrm{kW})$ & 27.45 & 21.86 & 16.19 & 15.57 & 26.04 \\
\hline PV Energy Production (kWh/day) & 355.752 & 283.3056 & 209.8224 & 201.7872 & 337.4784 \\
\hline DG Production (kWh/day) & 303.048 & 241.3344 & 178.7376 & 171.8928 & 287.4816 \\
\hline Energy Consumption kWh/day & 658.8 & 524.64 & 388.56 & 373.68 & 624.96 \\
\hline Energy Consumption kWh/Year & 240462 & 191494 & 141824 & 136393 & 228110 \\
\hline Solar PV $(\mathrm{kWp})$ & 89.2 & 71 & 53 & 50.6 & 84.6 \\
\hline Diesel Generator $(\mathrm{kW})$ & \multicolumn{5}{|c|}{120} \\
\hline PV panels (Units) & 262 & 209 & 155 & 149 & 249 \\
\hline Area $\left(\mathrm{m}^{2}\right)$ & 0.892 & 0.71 & 0.53 & 0.506 & 0.846 \\
\hline DC/AC inverter No. (27 kW/Unit) & 4 & 3 & 2 & 2 & 4 \\
\hline Total capital cost $(\mathrm{EGP})$ & 871177 & 703844 & 534711 & 520122 & 838039 \\
\hline Diesel consumption $(\mathrm{L} / \mathrm{y})$ & 61898 & 49275 & 36500 & 35113 & 58729 \\
\hline Generator renting cost (EGP/day) & \multicolumn{5}{|c|}{1155} \\
\hline Total fuel cost (EGP) & 618980 & 492750 & 365000 & 351130 & 587290 \\
\hline Total Electrical Production $(\mathrm{kWh} / \mathrm{y})$ & 273057 & 217425 & 161030 & 154863 & 259000 \\
\hline$\overline{A T L C C}$ & 1287193 & 1134216 & 978730 & 963345 & 1252097 \\
\hline LCOE (EGP/kWh) & 5.353 & 5.923 & 6.901 & 7.063 & 5.489 \\
\hline \multirow{2}{*}{ Parameters } & \multicolumn{5}{|c|}{ Well No. } \\
\hline & 6 & 7 & 8 & 9 & 10 \\
\hline Flow Rate (bbl./Day) & 125 & 425 & 250 & 220 & 165 \\
\hline Actual Power (kW) & 12.16 & 28.02 & 21.23 & 16.8 & 14.55 \\
\hline PV Energy Production (kWh/day) & 157.5936 & 363.1392 & 275.1408 & 217.728 & 188.568 \\
\hline DG Production (kWh/day) & 134.2464 & 309.3408 & 234.3792 & 185.472 & 160.632 \\
\hline Energy Consumption kWh/day & 291.84 & 672.48 & 509.52 & 403.2 & 349.2 \\
\hline Energy Consumption kWh/Year & 106522 & 245455 & 185975 & 147168 & 127458 \\
\hline Solar PV (kWp) & 39.5 & 91.1 & 69 & 54.6 & 47.2 \\
\hline Diesel Generator $(\mathrm{kW})$ & \multicolumn{5}{|c|}{120} \\
\hline PV panels (Units) & 117 & 268 & 203 & 161 & 139 \\
\hline Area $\left(m^{2}\right)$ & 0.395 & 0.911 & 0.69 & 0.546 & 0.472 \\
\hline DC/AC inverter No. (27 kW/Unit) & 2 & 4 & 3 & 2 & 2 \\
\hline Total capital cost (EGP) & 440338 & 884504 & 689076 & 548939 & 496349 \\
\hline Diesel consumption (L/y) & 27412 & 63182 & 47888 & 37887 & 32814 \\
\hline Generator renting cost (EGP/day) & \multicolumn{5}{|c|}{1155} \\
\hline Total fuel cost (EGP) & 274120 & 631820 & 478880 & 378870 & 328140 \\
\hline Total Electrical Production $(\mathrm{kWh} / \mathrm{y})$ & 120946 & 278694 & 211159 & 167097 & 144718 \\
\hline ATLCC & 878164 & 1301648 & 1118266 & 993972 & 937835 \\
\hline LCOE (EGP/kWh) & 8.244 & 5.303 & 6.013 & 6.754 & 7.358 \\
\hline
\end{tabular}




\subsubsection{Hybrid centralized generation system (HCGS)}

One of the main advantages of the centralized generation systems is the possibility of utilizing excess energy with respect to HDGS, whenever existed. To design a centralized generation system for this research case study, table 6 presents the overall field parameters which are needed to run the whole field. The flow rate is the main reference that is used to categorize the oil well, and it is the main factor that affects the power consumption in the system. Therefore, the whole field requires $200 \mathrm{~kW}$ to produce 2645 bbl./day. The centralized PV system generates $2592 \mathrm{kWh}$ per day, while the DG generates $2208 \mathrm{kWh}$ per day. Accordingly, the energy consumption for the whole field per day is 4800 $\mathrm{kWh} /$ day, which turns to $1752000 \mathrm{kWh}$ per year. The share of the energy produced in the system is set to the optimum value of 54\% for the PV side and $46 \%$ for diesel generation. The PV system requires 6500 $\mathrm{m} 2$ area to establish the $650 \mathrm{kWp}$ PV system that used $1912 \mathrm{PV}$ modules with a rating of $340 \mathrm{~W}$ to generate $2592 \mathrm{kWh}$ per day.

To design the HCGS, there are two main parameters that affect the design settings with respect to the model of the HDGS. These parameters are the rating of the inverters and the rating of the diesel generators. For the HCGS, one inverter is used with a $200 \mathrm{~kW}$ rating along with one diesel generator with a rating of $292 \mathrm{~kW}-365 \mathrm{kVA}$. The $292 \mathrm{~kW}$ diesel generator consumes 659 litres per day with 10 EGP per litter, which turn to a total cost of 2403530 EGP per year. The running cost (renting cost) of this diesel generator unit is 1700 EGP per day. Extra cables are added in the HCGS, added cost with respect to HDGS, to supply all loads from the same centralized source. The net cables cost in the HCGS is 7360000 EGP for $20 \mathrm{~km}$ cables with 368000 EGP per km, and the total capital cost of the whole system is 12333200 EGP. The cable cost in the HCGS is recorded as the highest parameter in the capital cost of the system with more than $59 \%$ of the total system cost. The total Levelized cost of energy for this centralized generation system is $2.56 \mathrm{EGP}$ per $\mathrm{kWh}$.

The reliability of the HCGS is lower than the HDGS as in case of system failure; the whole system will be a blackout. To avoid the production disturbance at any time, the backup system could be synchronized with the existing system to increase the HCGS reliability. By adding the backup system to the HCGS, the extra added parameters and the new setup configuration of the updated system is presented in table 7. The standby system is consisting of one inverter with a $200 \mathrm{~kW}$ rating and one diesel generator with $292 \mathrm{~kW}$ power output. These backup units are affecting the total capital cost with an increase of 252400 EGP than the normal HCGS. The new capital cost for the HCGS with the backup units is $12,585,600$ EGP, and the LCOE became 2.965 EGP/KWh.

Table 6. The Settings of the CGS for the Whole Field

\begin{tabular}{|c|c|c|c|}
\hline Parameters & Value & Parameters & Value \\
\hline Flow Rate (bbl./Day) & 2645 & Total Cables Distance $(\mathrm{km})$ & 20 \\
\hline Actual Power $(\mathrm{kW})$ & 200 & Total Cables Cost (EGP) & 7360000 \\
\hline PV Energy Production (kWh/day) & 2592 & No. of Diesel Generator (Unit) & 1 \\
\hline Diesel Generator Production (kWh/day) & 2208 & Diesel Generator (kW) & 292 \\
\hline Energy Consumption kWh/day & 4800 & Diesel Consumption (L/day) & 659 \\
\hline Energy Consumption kWh/Year & 1752000 & Diesel Consumption (L/year) & 240535 \\
\hline Solar PV (kWp) & 650 & Generator Renting Cost (EGP/day) & 1700 \\
\hline No. of PV Panels (Units) & 1912 & Generator Renting Cost (EGP/year) & 620500 \\
\hline PV Panel Rating (W) & 340 & Total Capital Cost (EGP) & 12333200 \\
\hline Area (m2) & 6500 & Total Fuel Cost (EGP/y) & 2405350 \\
\hline DC/AC Inverters Rating (kW) & 200 & Total Electrical Production $(\mathrm{kWh/y)}$ & 1989250 \\
\hline No. of DC/AC Inverters (/Unit) & 1 & ATLCC (EGP/year) & 4485120 \\
\hline Cables cost per km (EGP) & 368000 & LCOE (EGP/kWh) & 2.56 \\
\hline
\end{tabular}


Table 7. Backup System Parameters

\begin{tabular}{|c|c|}
\hline Parameters & Setting \\
\hline No. of Backup DC/AC Inverters (Unit) & 1 \\
\hline Backup DC/AC Inverter Rating (kW) & 200 \\
\hline No. of Backup Diesel Generator (Unit) & 1 \\
\hline Backup Diesel Generator (kW) & 292 \\
\hline New Total Capital Cost (EGP) & $12,585,600$ \\
\hline New LCOE (EGP/kWh) & 2.965 \\
\hline
\end{tabular}

\subsubsection{Comparison between the HDGS and the HCGS topologies}

Principally, both the HDGS and the HCGS have pros and cons in the technical and economical sides of this study. Both designs have been applied for the case study, and each one of them got their own configurations that fit SRP system needs. Table 8 lists the comparison between the HDGS, HCGS (with the backup units), and the currently running system (0\%-PV, 100\%-DG). The rental cost of both the Hybrid Distributed Generation System (HDGS) and the currently running system are the same, but the diesel consumption is different.

Table 8. Comparison between the HDGS, HCGS and the Existing System

\begin{tabular}{|c|c|c|c|}
\hline Parameters & Existing System & HDGS & HCGS \\
\hline Flow Rate (bbl./Day) & 2645 & 2645 & 2645 \\
\hline Actual Power $(\mathrm{kW})$ & 200 & 200 & 200 \\
\hline PV Energy Production (kWh/day) & - & 2592 & 2592 \\
\hline Diesel Generator Production (kWh/day) & 4800 & 2208 & 2208 \\
\hline Energy Consumption kWh/day & 4800 & 4800 & 4800 \\
\hline Energy Consumption kWh/Year & 1752000 & 1752000 & 1752000 \\
\hline Solar PV (kWp) & - & 650 & 650 \\
\hline PV panels (Units) & - & 1912 & 1912 \\
\hline PV Panel Rating (W) & - & 340 & 340 \\
\hline Area $(\mathrm{m} 2)$ & - & 6500 & 6500 \\
\hline No. of DC/AC Inverters (Unit) & - & 28 & 1 \\
\hline DC/AC Inverter Rating (kW) & - & 27 & 200 \\
\hline No. of Diesel Generator (Unit) & 10 & 10 & 1 \\
\hline Diesel Generator $(\mathrm{kW})$ & 120 & 120 & 292 \\
\hline Diesel consumption (L/day) & 2684 & 1235 & 659 \\
\hline Diesel consumption (L/y) & 979,660 & 450700 & 240535 \\
\hline Generator renting cost (EGP/day) & 11550 & 11550 & 1700 \\
\hline Generator renting cost (EGP/year) & $4,215,750$ & 4215750 & 620500 \\
\hline Extra Cables cost (EGP) & - & - & 7360000 \\
\hline Total capital cost (EGP) & - & $6,527,100$ & $12,585,600$ \\
\hline Total fuel cost (EGP/year) & 979,6600 & 4506980 & 2405350 \\
\hline Total Electrical Production (kWh/year) & 1987989 & 1987989 & 1989250 \\
\hline ATLCC (EGP/year) & $13,998,480$ & 10844880 & 4485120 \\
\hline LCOE (EGP/kWh) & 7.99 & 6.19 & 2.965 \\
\hline
\end{tabular}


This is due to that the currently running system mainly depends on the diesel generator only; therefore, the diesel consumption drops from 979,660 $\mathrm{L} / \mathrm{y}$ in the currently running system to $450700 \mathrm{~L} / \mathrm{y}$ in the HDGS. This definitely affects the ATLCC of the system and makes it fall from 13,998,480 EGP in the stand-alone DG to 10844880 EGP in the HDGS. Consequently, the LCOE of the existing system was 7.99 EGP/kWh, while it is only 6.19 EGP/kWh in the HDGS.

By comparing the HDGS with HCGS: in HDGS, the rate of the used inverter was $27 \mathrm{~kW}$ with a total of 28 inverters that have been used to cover the system needs. Meanwhile, in the HCGS, the inverter rate was $200 \mathrm{~kW}$ with only one inverter in the system. The HDGS needs 10-diesel generators with a $120 \mathrm{~kW}$ rating to supply the 10 -sucker rod pumping systems, while the HCGS requires only one diesel generator with $292 \mathrm{~kW}$ rating. The diesel consumption drops from 1235 litres per day in the HDGS to 659 litres per day in the HCGS due to the optimum selection of the diesel generator size. The reduction in the number of generators caused a drop in the yearly rental cost from 4,215,750 EGP per year in the HDGS to 620,500 EGP per year in the HCGS. This shows that the rental cost in the case of the HDGS is more than six times than of the HCGS.

The capital cost of the HDGS is 6,527,100 EGP, while it is 12,585,600 EGP for the HCGS with an increase of 6,058,500EGP (92\%) more than the HDGS. The parameter that has the most significant effect on the total capital cost of the HCGS than the HDGS is the cost of cables with more than $59 \%$ of the total system capital cost. Meanwhile, The Operating cost has more effect than the capital cost over the total system cost; therefore, the LCOE of the HCGS is 2.965 EGP per kWh while it is 6.19 EGP per $\mathrm{kWh}$ for the HDGS. The overall conclusion states that the HDGS can save $22.5 \%$ in LCOE than the currently running system, while the HCGS can save $62.8 \%$. Accordingly, we recommend the utilization of HCGS in such configurations.

\section{Conclusion}

Oil \& gas sites are mostly very far from national grid; therefore, the required energy is provided by the diesel system. It is clearly known that conventional energy sources such as diesel generators have some drawbacks, such as carbon dioxide emissions and the high operating and maintenance cost. Therefore, integrating the renewable energy with the conventional energy sources limits its demerits. Additionally, the integration limits the problem of supplying fuel to the remote areas of the SRPs sites. All these parameters will affect in the total production cost of the oil, as well as the environmental conditions.

Herein, we introduce a novel optimized system based on both PV as a renewable energy resource in addition to DG as a conventional source. The optimization process is considered from the PV/DG contribution percentage where $54 \%$ to $46 \%$ optimum system was concluded. Then, two various topologies were demonstrated with a centralized architecture against a distributed one. LCOE was considered the main evaluating parameter, reaching an overall reduction of $62 \%$ with referring to the current DG $100 \%$ running system while proposing HCGS. While still the HDGS recorded enhanced LCOE than the running alternative but still significantly higher than the HCGS (nearly twice).

The work implemented in this study can be generalized either in terms of the location or the artificial lifting systems to include a set of varieties. Moreover, this back-stage optimizer can be interfaced with an appropriate GUI, to be deployed as an online pre-sizing tool.

\section{Nomenclature}

\begin{tabular}{|l|l|l|}
\hline Parameter & Defination & Unit \\
\hline $\boldsymbol{\beta}_{\mathbf{i}}$ & $\begin{array}{l}\text { Dummy weighting } \\
\text { factor in WCOT } \\
\text { fitness function }\end{array}$ & 1 \\
\hline $\boldsymbol{\eta}_{\mathbf{B}}$ & The battery efficiency & 1 \\
\hline $\boldsymbol{\eta}_{\text {inv }}$ & Inverter efficiency & 1 \\
\hline $\boldsymbol{\eta}_{\mathbf{R}}$ & $\begin{array}{l}\text { Voltage regulator } \\
\text { efficiency }\end{array}$ & 1 \\
\hline $\boldsymbol{Z}_{\mathbf{L C O E}}$ & $\begin{array}{l}\text { A geometric average } \\
\text { for these three LCOE } \\
\text { parameters is } \\
\text { introduced } \\
\text { optimize } \\
\text { WCOT }\end{array}$ & EGP/KWh \\
\hline $\mathbf{A T L C C}$ & $\begin{array}{l}\text { The Annualized Total } \\
\text { Life Cycle Cost }\end{array}$ & EGP \\
\hline $\mathbf{C}_{\mathbf{c a p}}$ & $\begin{array}{l}\text { The total capital cost } \\
\text { The capital costs }\end{array}$ & EGP \\
\hline $\mathbf{C}_{\mathbf{c a p}, \mathbf{a}}$ & EGP \\
\hline $\mathbf{C}_{\mathbf{c a p}, \mathbf{B a t}}$ & $\begin{array}{l}\text { The total capital cost } \\
\text { for battery }\end{array}$ & EGP \\
\hline $\mathbf{C}_{\mathbf{c a p}, \mathbf{C}}$ & $\begin{array}{l}\text { The total capital cost } \\
\text { for the controller }\end{array}$ & EGP \\
\hline $\boldsymbol{C}_{\boldsymbol{c a p}, \mathbf{D G}}$ & $\begin{array}{l}\text { The total capital cost } \\
\text { for diesel generator }\end{array}$ & EGP \\
\hline $\mathbf{C}_{\mathbf{c a p}, \mathbf{I n v}}$ & $\begin{array}{l}\text { The total capital cost } \\
\text { for inverters }\end{array}$ & EGP \\
\hline $\mathbf{C}_{\mathbf{c a p}, \mathbf{P V}}$ & $\begin{array}{l}\text { The total capital cost } \\
\text { for PV array }\end{array}$ & EGP \\
\hline $\mathbf{C}_{\mathbf{c a p}, \mathbf{O C}}$ & $\begin{array}{l}\text { The total capital other } \\
\text { costs }\end{array}$ & EGP \\
\hline
\end{tabular}




\begin{tabular}{|c|c|c|}
\hline $\mathrm{C}_{\mathbf{o} \& \mathrm{~m}}$ & $\begin{array}{l}\text { The total operating } \\
\text { and maintenance } \\
\text { expenses }\end{array}$ & EGP \\
\hline $\mathbf{C}_{\mathbf{0} \& \mathrm{~m}, \mathrm{a}}$ & $\begin{array}{l}\text { The operation and } \\
\text { maintenance costs }\end{array}$ & EGP \\
\hline$C_{o \& m, B a t}$ & $\begin{array}{l}\text { The total operating } \\
\text { and maintenance cost } \\
\text { for battery }\end{array}$ & EGP \\
\hline$C_{o \& m, C}$ & $\begin{array}{l}\text { The total operating } \\
\text { and maintenance cost } \\
\text { for the controller }\end{array}$ & EGP \\
\hline$C_{o \& m, D G}$ & $\begin{array}{l}\text { The total operating } \\
\text { and maintenance cost } \\
\text { for diesel generator }\end{array}$ & EGP \\
\hline $\mathrm{C}_{\mathbf{o} \& \mathrm{~m}, \mathrm{Inv}}$ & $\begin{array}{l}\text { The total operating } \\
\text { and maintenance cost } \\
\text { for inverter }\end{array}$ & EGP \\
\hline$C_{o \& m, O C}$ & $\begin{array}{l}\text { The total operating } \\
\text { and maintenance } \\
\text { other costs }\end{array}$ & EGP \\
\hline $\mathrm{C}_{\mathbf{0} \& \mathrm{~m}, \mathrm{PV}}$ & $\begin{array}{l}\text { The total operating } \\
\text { and maintenance cost } \\
\text { for PV array }\end{array}$ & EGP \\
\hline $\mathrm{C}_{\text {rep,a }}$ & $\begin{array}{l}\text { The replacement } \\
\text { costs }\end{array}$ & EGP \\
\hline $\mathrm{C}_{\mathrm{s}, \mathrm{a}}$ & The salvage value & EGP \\
\hline DOD & Depth of discharge & 1 \\
\hline $\mathbf{E}_{\mathrm{B}}$ & $\begin{array}{ll}\begin{array}{l}\text { Battery } \\
\text { capacity }\end{array} & \text { storage } \\
\end{array}$ & $\mathrm{Wh}$ \\
\hline $\mathbf{E}_{\mathbf{L}}$ & $\begin{array}{l}\text { The total energy } \\
\text { demand per day }\end{array}$ & $\mathrm{Wh}$ \\
\hline$F_{s}$ & Safety factor & 1 \\
\hline $\mathrm{G}$ & Specific gravity & 1 \\
\hline I & Electric Current & $\mathrm{A}$ \\
\hline $\mathbf{I}_{\mathrm{B}}$ & $\begin{array}{l}\text { the battery storage } \\
\text { ampere hour }\end{array}$ & $\mathrm{Ah}$ \\
\hline $\mathbf{H}_{\mathrm{b}}$ & $\begin{array}{l}\text { The brake } \\
\text { horsepower }\end{array}$ & $\mathrm{Hp}$ \\
\hline $\mathbf{H}_{\text {hydr }}$ & $\begin{array}{l}\text { The hydraulic } \\
\text { horsepower required } \\
\text { for lifting the liquid }\end{array}$ & $\mathrm{Hp}$ \\
\hline $\mathbf{H}_{\mathrm{f}}$ & $\begin{array}{ll}\text { The friction } \\
\text { horsepower }\end{array}$ & $\mathrm{Hp}$ \\
\hline $\mathbf{L}_{\text {dyn }}$ & $\begin{array}{l}\text { The dynamic liquid } \\
\text { level in the well }\end{array}$ & $\mathrm{Ft}$ \\
\hline $\mathbf{L}_{\mathbf{s}}$ & The total lifetime & Years \\
\hline$L C O E$ & $\begin{array}{l}\text { The Levelized Cost of } \\
\text { Energy }\end{array}$ & EGP/KWh \\
\hline $\mathrm{LCOE}_{\mathrm{DG}}^{\varepsilon}$ & $\begin{array}{l}\text { The DG system } \\
\text { Levelized Cost of } \\
\text { Energy }\end{array}$ & EGP/KWh \\
\hline
\end{tabular}

\begin{tabular}{|l|l|l|}
\hline $\mathbf{L C O E}_{\mathbf{B}-\mathbf{D C}}^{\boldsymbol{\varepsilon}}$ & $\begin{array}{l}\text { The storage system } \\
\text { Levelized Cost of } \\
\text { Energy }\end{array}$ & EGP/KWh \\
\hline $\mathbf{L C O E} \mathbf{P V}$ & $\begin{array}{l}\text { The PV system } \\
\text { Levelized Cost of } \\
\text { Energy }\end{array}$ & EGP/KWh \\
\hline $\mathbf{N}$ & Pump speed & spm \\
\hline $\mathbf{n d r}$ & $\begin{array}{l}\text { The net of inflation } \\
\text { rate discount }\end{array}$ & 1 \\
\hline $\mathbf{V}$ & Voltage & $\mathrm{V}$ \\
\hline $\mathbf{V}_{\mathbf{B}}$ & The battery voltage & $\mathrm{V}$ \\
\hline $\mathbf{P}_{\mathbf{M}}$ & SRP motor rating & $\mathrm{KW}$ \\
\hline $\boldsymbol{P}_{\mathbf{P V}}$ & Photovolatic power & $\mathrm{KW}$ \\
\hline $\boldsymbol{p f}$ & Power factor & 1 \\
\hline $\boldsymbol{P S H}$ & Peak sun hours & hrs \\
\hline $\mathbf{Q}$ & Flow rate & bbl./Day \\
\hline $\mathbf{R M S E}$ & $\begin{array}{l}\text { The root mean square } \\
\text { error }\end{array}$ & 1 \\
\hline $\mathbf{S}$ & Stroke length & in \\
\hline $\mathbf{S}_{\mathbf{f}}$ & $\begin{array}{l}\text { PV system safety } \\
\text { factor }\end{array}$ & 1 \\
\hline $\mathbf{W r}$ & $\begin{array}{l}\text { Weight of sucker rod } \\
\text { string }\end{array}$ & lb. \\
\hline
\end{tabular}

References:

[1] K. E. Okedu, H. A. Nadabi, and A. Aziz, "Prospects of Solar Energy in Oman: case of oil and gas industries," International Journal of Smart Grid, vol. 3, no. 3, 2019, pp. 138-151.

[2] M. Ouki, "Egypt - a return to a balanced gas market?," OIES paper: NG 131, Oxford Institute for Energy Studies, 2018. Available from: https://doi.org/10.26889/978178467112 9

[3] S. Levoniuk, and H. E. Taki, "Selection strategy for the optimal artificial lift method (on the example of Novotroitsk field, Ukraine)," National Technical University, 2020, pp. 6-13.

[4] B. Bintarto, R. R. Auliya, R. A. M. Putra, A. S. Pradipta, and R. A. Kurnia, "Production Data Analysis and Sonolog for Determining Artificial Lift Design and Well Characteristic," Journal of Petroleum Geothermal Technology, vol. 1, no. 1, 2020, pp. 28-35.

[5] C. Kandziora, "Applying artificial intelligence to optimize oil and gas 
production," in Offshore Technology Conference, Texas, 2019. Available from: https://doi.org/10.4043/29384-MS

[6] E. O. a. Gas, "GE Oil \& Gas and Petrojet Mark the Manufacture of 1000th Pumping Unit for Oil and Gas sector in Egypt," 2014. Available from: https://egyptoil-gas.com/features/ge-oilgas-and-petrojet-mark-the-manufactureof-1000th-pumping-unit-for-oil-andgas-sector-in-egypt/

[7] A. Abdelmaksoud, H. F. Ewida, G. H. ElHabaak, and A. T. Amin, "3D structural modeling of the Upper Bahariya Member in Abu Gharadig oil and gas field, North Western Desert, Egypt," Journal of African Earth Sciences, vol. 150, 2019, pp. 685-700.

[8] A. Tarshan, and S. Shimanskiy, "Petroleum system modelling and identification of promising oil and gas bearing objects in the eastern part of the Gulf of Suez, Egypt," Russian Journal of Earth Sciences, vol. 19, no. 4, 2019.

[9] S. Rolland, and G. Glania, "Hybrid minigrids for rural electrification: lessons learned," Alliance for Rural Electrification, 2011. Available from: https://www.ruralelec.org/sites/defa ult/files/hybrid_minigrids_for_rural_el ectrification_2014.pdf

[10] D. Grassian, and D. B. Olsen, "Practical Applications of Net Energy Analysis of Upstream Oil and Gas Processes," Journal of Energy Resources Technology, vol. 143, no. 6, 2021.

[11] A. A.-A. M. Abdulhameed, V. Y. Kornilov, and A. Gorodnov, "Optimal operation of electrical power generators for oil wells operated by artificial lifting at Rumila field," Известия выстих учебных заведений. ПРОБЛЕМЫ ЭНЕРГЕТИКИ, vol. 20, no. 11-12, 2018.

[12] Y. Choi, C. Lee, and J. Song, "Review of renewable energy technologies utilized in the oil and gas industry," International
Journal of Renewable Energy Research, vol. 7, no. 2, 2017, pp. 592-598.

[13] R. Moussa, "Installing Piezoelectric tiles in Children Outdoor Playing areas to Create Clean \& Healthy Environment; Case Study of El-Shams Sporting Club, Cairo_Egypt," WSEAS Transactions on Environment and Development, vol. 16, 05/25, 2020, pp. 471-479.

[14] R. R. Moussa, "The Effect of PiezoBumps on Energy Generation and Reduction of the Global Carbon Emissions," WSEAS Transactions on Environment Development, vol. 15, no. 46, 2019, pp. 430-437.

[15] M. J. Pickl, "The renewable energy strategies of oil majors - From oil to energy?," Energy Strategy Reviews, vol. 26, 2019, pp. 100370.

[16] J. Wang, J. O'Donnell, and A. R. Brandt, "Potential solar energy use in the global petroleum sector," Energy, vol. 118, 2017, pp. 884-892.

[17] T. Khatib, A. Mohamed, K. Sopian, and M. Mahmoud, "Optimal sizing of building integrated hybrid PV/diesel generator system for zero load rejection for Malaysia," Energy and Buildings, vol. 43, no. 12, 2011, pp. 3430-3435.

[18] R. CIMINO, V. BROCCO, F. CASTALDO, G. De GHETTO, M. FAVARETTO, and T. AKMAL, "Deploying a Solar Hybrid Technology in a Remote Oil and Gas Production Site," Journal of the Japan Institute of Energy, vol. 94, no. 10, 2015, pp. 11631168.

[19] T. Iqbal, C. A. Osaretin, and S. Butt, "Optimal sizing and techno-economic analysis of a renewable power system for a remote oil well," AIMS Electronics Electrical Engineering, vol. 4, no. 2, 2020, pp. 132-153.

[20] A. Mansour, J. Abdallah, and M. Obeidat, "An efficient intelligent power detection method for photovoltaic system," International Journal of 
Circuits, Systems Signal Processing, vol. 14, 2020, pp. 686-699.

[21] Z. S. Yue Lin, Bai Jing, Kanae Shunshoku, "A Multi Fusion Data Mining Algorithm for Solar Energy Efficiency," International journal of circuits, systems and signal processing, vol. 14, 2020, pp. 499-510.

[22] B. C. Craft, W. R. Holden, and E. D. Graves, Well Design: Drilling and Production: Prentice-Hall, 1962.

[23] M. Atef, M. Abdullah, T. Khatib, and M. Romlie, "Utilization of Artificial Neural Networks to Improve the Accuracy of a Hybrid Power System Model," in 2019 IEEE Student Conference on Research and Development (SCOReD), pp. 284288.

[24] T. Khatib, and W. Elmenreich, Modeling of Photovoltaic Systems Using MATLAB: Simplified Green Codes: John Wiley \& Sons, 2016.

[25] T. ECONOMICS, "Egypt: Inflation rate from 1984 to 2021." Available from: https://www.statista.com/statistics/3773 54/inflation-rate-in-egypt/

[26] IRENA (2018), Renewable Energy Outlook: Egypt, International Renewable Energy Agency, Abu Dhabi. Available from:https://www.irena.org//media/Files /IRENA/Agency/Publication/2018/Oct/I RENA_Outlook_Egypt_2018_En.pdf

[27] M. M. Zarie, P. Makeen, S. O. Abdellatif, I. Mahmoud, and T. Abdel-Salam, "Techno-economic Feasibility of Photovoltaic System for an Educational Building in Egypt:(Case Study)," in 2019 International Conference on Innovative Trends in Computer Engineering (ITCE), 2019, pp. 521-525.

[28] N. M. Elsayed, R. A. Swief, S. O. Abdellatif, and T. S. Abdel-Salam, "Photovoltaic Applications for Lighting Load Energy Saving: Case Studies, Educational Building," in 2019 International Conference on Innovative
Trends in Computer Engineering (ITCE), 2019, pp. 564-569.

[29] M. Sadeq, and S. Abdellatif, "PV-ON: An online/bilingual PV sizing tool for grid-connected system, case studies in Egypt," International Transactions on Electrical Energy Systems, 2021, pp. e12910.

[30] M. Sadeq, S. O. Abdellatif, W. R. Anis, and H. A. Ghali, "Development of presizing techno-economic Matlab code for grid-connected PV system, using four cities in Egypt," in New Concepts in Solar and Thermal Radiation Conversion III, 2020, pp. 114960R.

[31] M. Elkasrawy, P. Makeen, S. O. Abdellatif, and H. A. Ghali, "Optimizing electric vehicles station performance using AI-based decision maker algorithm," in Emerging Topics in Artificial Intelligence 2020, pp. $114691 \mathrm{~W}$.

[32] T. Chai, and R. R. J. G. m. d. Draxler, "Root mean square error (RMSE) or mean absolute error (MAE)?-Arguments against avoiding RMSE in the literature," vol. 7, no. 3, 2014, pp. 1247-1250.

Author Contribution: All the author have made substantive contributions to the manuscript. Sameh O. Abdullatif has made a significant contribution to the conception and design of the work. Mohammad M. El-Yamany has made a substantial contribution to the data collection, analysis, and interpretation. Hani A. Ghali drafted the manuscript and revised it.

\section{Creative Commons Attribution License 4.0 (Attribution 4.0 International, CC BY 4.0)}

This article is published under the terms of the Creative Commons Attribution License 4.0

https://creativecommons.org/licenses/by/4.0/deed.en_US 